\title{
LA RESPONSABILIDAD Y LA UNIVERSIDAD A LA LUZ DE LA LAUDATO SÍ PARA LOGRAR LOS OBJETIVOS DEL DESARROLLO SOSTENIBLE
}

Dr. Juan Víctor MESEGUER SÁNCHEZ²

Ana María CERÓN MORALES ${ }^{3}$

\begin{abstract}
RESUMEN
Revisadas los esfuerzos realizados por la comunidad internacional a través del reconocimiento de la necesaria protección de la naturaleza, la encíclica laudatio si contribuye de forma sustancial a la senda marcada por los Tratados, conferencias y declaraciones internacionales en la protección de la naturaleza, el logro de los Objetivos del Desarrollo Sostenible, a la reducción del cambio climático, y al Derecho Ambiental en sentido amplio. El Papa propone a la humanidad un cambio de conducta, invita a una transformación, a una conversión ecológica a través de un diálogo interreligioso con la sostenibilidad y la ecología integral como referentes. En este sentido, la Responsabilidad Social
\end{abstract}

\footnotetext{
${ }^{1}$ Doctora en Derecho por la Universidad Complutense de Madrid. Director Dpto Derecho Ambiental. Universidad Católica San Antonio de Murcia (UCAM), Murcia, Espanha.

${ }^{2}$ Director Cátedra Internacional de Responsabilidad Social Corporativa. Universidad Católica San Antonio de Murcia (UCAM), Murcia, Espanha.

${ }^{3}$ Doctoranda Cátedra Internacional RSC Universidad Católica San Antonio de Murcia (UCAM), Murcia, Espanha.
} 
Universitaria se manifiesta como elemento vertebrador del conocimiento multidisciplinar e instrumental para el desarrollo de la conciencia ecológica y la defensa y protección de los recursos naturales y la biodiversidad.

PALABRAS CLAVE: Encíclica Laudato Sí, Derecho Ambiental, Objetivos del Desarrollo Sostenible, Responsabilidad Social Universitaria, Cambio climático.

\begin{abstract}
Revised the efforts made by the international community through the recognition of the necessary protection of nature, the encyclical laudatio if it contributes substantially to the path marked by the Treaties, conferences and international declarations in the protection of nature, the achievement of the Sustainable Development Goals, the reduction of climate change, and Environmental Law in a broad sense. The Pope proposes to humanity a change of behavior, invites a transformation, an ecological conversion through an interreligious dialogue with sustainability and integral ecology as referents. In this sense, University Social Responsibility is manifested as the backbone of multidisciplinary and instrumental knowledge for the development of ecological awareness and the defense and protection of natural resources and biodiversity.

KEYWORDS: Encyclical letter, Laudato si, Environmental Law, Sustainable Development Goals, University Social Responsibility, Climate Change.
\end{abstract}

\title{
SUMARIO
}

1. ANTECEDENTES. 2. APORTACIONES DE LA ENCÍCLICA "LAUDATIO SI" A LA DEFENSA Y PROTECCIÓN DE LA NATURALEZA 2.1. Tecnología, ecología y humanidad 2.2. Cuidar de la casa común, obligación de todos 3. CONOCIMIENTO Y RESPONSABILIDAD SOCIAL UNIVERSITARIA COMO EJES DEL NUEVO PARADIGMA SOCIAL CONTRA EL CAMBIO CLIMÁTICO E IMPULSO DE LA ECONOMÍA CIRCULAR. 4. CONCLUSIONES. 5. BIBLIOGRAFIA.

\section{$1 \quad$ ANTECEDENTES}

Interesa aquí retroceder hasta la época de los 70, marcada por el despertar del movimiento verde y de la regulación ambiental que también acogió la Iglesia Católica , así en 1971, ya el Papa Pablo VI se refería a la problemática ecológica como una crisis dramática fruto de la actividad descontrolada del ser humano ${ }^{4}$. Un año más tarde, en Estocolmo se reunieron 113 Estados en la primera Conferencia de las Naciones Unidas sobre el Medio Humano. En la capital sueca, las Naciones Unidas captaron el mensaje internacional sobre el desafío que planteaba el paradigma ecológico ${ }^{5}$. La Conferencia impulsó, la creación en múltiples Estados, casi

\footnotetext{
${ }^{4}$ En este sentido indica de forma expresa el actual Pontífice "Debido a una explotación inconsiderada de la naturaleza, el ser humano corre el riesgo de destruirla y de ser a su vez víctima de esta degradación" FRANCISCO, Vaticano II, Laudatio Si, 2015, LS.2.

${ }^{5}$ La Asamblea General de las Naciones Unidas, en 1968, motivada por el detrimento de la calidad de vida de las personas, producido por los efectos negativos que estaban haciéndose patentes debido a una mala gestión de los recursos, convocó la primera reunión internacional sobre el medio ambiente en el ámbito internacional. Para un mayor desarrollo de la cuestión véase A/CONF.48/14/Rev.1 Nueva York 1973.
} 
todos ellos pertenecientes al mundo desarrollado, de un régimen institucional para la protección del entorno vital. Así vio la luz el compromiso de los Estados a garantizar el derecho de los seres humanos a un medio ambiente de calidad, como su responsabilidad para protegerlo y mejorarlo en beneficio de las generaciones presentes y futuras, adoptándose un Plan de acción con ciento seis recomendaciones dirigidas a los gobiernos y las distintas organizaciones internacionales para cimentar la nueva vía que la Conferencia suponía en materia de protección y salvaguarda del ambiente. Esta Declaración se conecta directamente con el principio que reconoce el derecho fundamental a la libertad, la igualdad y el disfrute de condiciones de vida adecuadas en un medio de calidad tal que le permita llevar -al hombre/humanidad - una vida digna y gozar de su bienestar. $^{6}$

En colaboración con el proceso legislativo e institucional de los Estados, las Organizaciones Internacionales han jugado un importante papel en la elaboración y desarrollo de las normas de protección ambiental ${ }^{7}$ lo que suscitó la denominada concienciación ecológica que se cristalizó veinte años más tarde en la Conferencia de las Naciones Unidas sobre Medio Ambiente y Desarrollo Sostenible de Río de Janeiro en 1992. Los resultados formales de la Conferencia fueron por una parte los Convenios

\footnotetext{
${ }^{6}$ Ver "Informe de la Conferencia de las Naciones Unidas sobre el Medio Humano" Doc. N.U. A/Conf.48/14/rev nº 1 y ONU Crónica mensual, julio de 1972 págs 95 y ss. y a RODRÍGUEZ VÁZQUEZ DE PRADA,"La Conferencia de Estocolmo sobre Medio Ambiente" en RAP,n ${ }^{\circ}$ 68,Madrid,1972 pags 381 y ss Cit por MÉNDEZ ROCASOLANO M.:Ambiente y Derecho Ambiental Concepto y Fuentes Rodela , 2005 donde la profesora pone de manifiesto el significado y alcance de las primeras declaraciones y los principios orientadores de derecho ambiental internacional. Págs 149 a 160 .

${ }^{7}$ Tras una década se realizó una evaluación sobre los resultados de la Conferencia y en ella se dejó constancia del incumplimiento del Plan de Acción a pesar del incremento en la comunidad internacional de la consciencia sobre la problemática ambiental, desde entonces hasta ahora hemos visto pasar el tiempo y progresar la degradación ambiental. En 1987, en el Informe Brundtlan se publicó la definición de desarrollo sostenible y supuso un gran avance en el tema de desarrollo humano. Como es de todos conocido propone "un desarrollo que satisfaga las necesidades de la generación presente sin comprometer la capacidad de abastecer las necesidades de generaciones futuras". Se percibe como la solución, ya que no era posible continuar consumiendo de manera ilimitada los recursos naturales limitados.Mientras que los países desarrollados centran su preocupación en los problemas de la capa de ozono, los cambios climáticos, la contaminación marítima, el comercio y tratamiento de residuos etc., los que están en desarrollo ponen el acento en el hambre y la pobreza, los medios para asegurarse agua potable, la mejora de las áreas rurales etc.Parece que los Objetivos del Desarrollo Sostenible reducen esas diferencias en las prioridades que, entendiendo que ahora son de todos y del Planeta, dificultaban la realización de planes comunes. En cumplimiento de las recomendaciones de Estocolmo, la Asamblea General de la ONU estableció en el mismo año un "Consejo de Administración para los Programas del Medio ambiente" (PNUMA) con sede en Nairobi, una Secretaria de Medio Ambiente encabezada por un Director ejecutivo, y un Fondo ambiental que se nutriría con contribuciones voluntarias MÉNDEZ ROCASOLANO M.: Ibidem.
} 
o acuerdos de carácter jurídico, como la Convención sobre Cambio Climático y el Convenio sobre la Diversidad Biológica, y además los textos o acuerdo aceptados por los países presentes, entre los que destacan la "Declaración de Río sobre Medio Ambiente y Desarrollo, la Declaración de Principios sobre los bosques y la Agenda $21 .^{8}$

En el recorrido de los Tratados Internacionales, destaca el Derecho ambiental de la Unión Europea y la intensa actividad legislativa e institucional de los países con sensibilidad por la protección de la naturaleza donde sin dejar de lado notables actuaciones de países concretos como los Escandinavos, Canadá y Japón destacamos la aportación de Alemania al desarrollo de la sensibilidad y la regulación ecológica a través de su partido verde ${ }^{9}$. Igualmente se manifiesta la preocupación de la Iglesia Católica en el transcurso de las denominadas por Méndez Rocasolano décadas de concienciación, puesta en valor y juridificación de la materia ambiental ${ }^{10}$. En este sentido, Juan Pablo II en la Jornada Mundial de la Paz del 90, señaló de manera especial la degradación ambiental durante sus años de pontificado, en diferentes ocasiones abordó esta cuestión afirmando que "la destrucción del ambiente humano es algo muy serio, porque Dios no sólo le encomendó el mundo al ser humano, sino que su propia vida es un don que debe ser protegido de diversas formas de degradación. Toda pretensión de cuidar y mejorar el mundo supone cambios profundos en los estilos de vida, los modelos de producción y de consumo, las estructuras consolidadas de poder que rigen hoy la sociedad" 11 .

El cambio de siglo estreno la Cumbre del Milenio del año 2000 firmada por los líderes de los países del ámbito internacional que acordaron los ocho Objetivos de Desarrollo del Milenio, precedente inmediato de los actuales Objetivos del Desarrollo Sostenible ${ }^{12}$, que ahora bajo el marco de

\footnotetext{
${ }^{8}$ La agenda 21 estableció el primer plan completo y detallado considerándose el anteproyecto de programa de actuación referente al desarrollo sostenible. Cfr. The global partnership; a guide to Agenda 21, Naciones Unidas, Ginebra, 1992.

9 Como indica CASTELLS hay un océano de "fuentes del partido alemán" seguimos sus recomendaciones de consulta en la La Era de la información: economía, sociedad y cultura, Volumen 2 Siglo XXI, 2004 pág 144 , para una visión actual de los verdes en Europa véase su página web https://europeangreens.eu/

${ }^{10}$ MÉNDEZ ROCASOLANO M. "Algunas consideraciones sobre la fundamentación axiológica del derecho a un ambiente adecuado para el desarrollo de la persona" en Estudios de teoría del Estado y derecho constitucional en honor de Pablo Lucas Verdú / coord. por Raúl Morodo Leoncio, Pedro de Vega García, Vol. 3, 2001.

${ }^{11}$ FRANCISCO, Carta encíclica Laudato si, sobre el cuidado de la casa común, 24 mayo, 2015.

${ }^{12}$ Desde el año 2000 se han conseguido algunos logros, la reducción del número de personas que vivían en pobreza extrema, una mejora en la nutrición, reconocimiento del derecho humano al agua y al
} 
la economía circular pretenden fundamentalmente reducir los efectos del cambio climático y lograr avances reales para la humanidad más desfavorecida. En el año 2005, el Compendio de la Doctrina Social de la Iglesia $^{13}$ en su capítulo X "Salvaguardar el medio ambiente", hacía referencia a los problemas en la custodia de la creación y Benedicto XVI conocido como "Papa de la Ecología", continuo con esta preocupación" ${ }^{14}$.

El protocolo de Kyoto y sus revisiones llevaron hasta el 2015 la preocupación que en la Convención de Paris culminó con el que ha sido el paso más firme dentro del derecho ambiental internacional para acabar con la emisión de gases efecto invernadero y actuar globalmente contra el cambio climático con la vista puesta primero en el año 2020 , ahora en el 2030 con la intención de fijarse como meta el 2050.

\section{APORTACIONES DE LA ENCÍCLICA LAUDATIO SI A LA DEFENSA Y PROTECCIÓN DE LA NATURALEZA}

El Papa Francisco, sensible con el comportamiento irresponsable y egoísta del ser humano y la degradación del medioambiente que pone en peligro a la creación y sus criaturas ha publicado la encíclica Laudato Si dedicada de forma íntegra al cuidado de la "casa común", el desarrollo

\footnotetext{
saneamiento, asistencia médica básica y medicamentos, educación básica...Lamentablemente, estos avances no se produjeron en todos los países por igual y países como África y Asia apenas avanzaron como indican HANSON, .K T. PUPLAMPU K. P., SHAW T. M. From Millennium Development Goals to Sustainable Development Goals en Development Goals to Sustainable Developm Goals: Rethinking African Development, Ed. Routledge, The International Political Economy of New Regionalisms Series, 2017

${ }^{13}$ No olvidamos aquí la crítica recibida desde una incompleta interpretación por parte del ecologismo anticlerical que pone de manifiesto la postura explotadora de la tradición cristiana basada en "Dios los bendijo y les dijo: Sean fecundos y multiplíquense. Llenen la tierra y sométanla. Ejerzan dominio sobre los peces del mar, sobre las aves del cielo y sobre todo ser viviente que se mueve sobre la tierra." (Génesis 1,28). Si este texto se interpreta de forma literal como un sometimiento y dominio radical, es ahí donde surgen las posiciones contrariadas puesto que supondría una explotación radical, pero esta postura no es la realidad de la Doctrina Social de la Iglesia y el Papa Francisco, sitúa el cuidado de la creación dentro ese ámbito de la Doctrina.

${ }^{14}$ En su encíclica Caritas in veritate 2009 abordó temas en torno a la ecología como la estrecha relación que surge entre el trato a la naturaleza y las personas, que reconoce la belleza de la creación. En concreto el Papa mostró dicha preocupación en lo que respecta a la emisión de gases en la Ciudad del Vaticano y la reforestación de una isla próxima al río Tisza desertizada tras la catástrofe medioambiental que padeció en el año 2000.En este sentido dice Francisco "con paternal preocupación, nos invitó a tomar conciencia de que la creación se ve perjudicada donde nosotros mismos somos las últimas instancias, donde el conjunto es simplemente una propiedad nuestra y el consumo es sólo para nosotros mismos. El derroche de la creación comienza donde no reconocemos ya ninguna instancia por encima de nosotros, sino que sólo nos vemos a nosotros mismos" FRANCISCO, Op.cit LS, 13.
} 
humano integral y la ética medioambiental ${ }^{15}$. A continuación reflexionaremos sobre los impactos que ha generado y los desafíos a los que se enfrenta. Con la mirada puesta en la próxima década, se hace un fuerte llamamiento a que todos los países lleven a cabo los esfuerzos necesarios para alcanzar los nuevos objetivos de desarrollo sostenible y erradicar así la pobreza, la desigualdad y la degradación medioambiental ${ }^{16}$.

En palabras del Rabino Sergio Bergman, Laudato Si tiene la virtud de volver sobre los textos originales de la tradición judeocristiana (...), y en ese punto el trabajo de Francisco nos invita a cerrar un recorrido de dos mil años volviendo sobre ideas y conceptos que nuestros antepasados tenían muy claras en aquella época...Esta encíclica pone en evidencia las tres dimensiones de Francisco como líder, maestro y estadista; porque nos enseña, nos impulsa hacia un cambio necesario y propone de manera clara varios objetivos que debieran convertirse en políticas de Estado" ${ }^{17}$. Así plantea una reflexión desde la creencia de que la conversión ecológica implica modificar nuestra forma de vida, de pensar y actuar en distintos ámbitos: personal, familiar, económico y político.

De la lectura de la encíclica se extrae la necesidad de establecer un diálogo y superar el distanciamiento entre la teología y el resto de ciencias en las que se basa la ecología. Aplicar una metodología holística, transversal y multidisciplinar que supere razonamientos puramente

\footnotetext{
${ }^{15}$ El 13 de Marzo de 2013, Jorge Bergoglio tras su elección como Papa escogió el nombre de Francisco, tomando como modelo a San Francisco de Asís, por su amor a los pobres y a la naturaleza. En este sentido se pone de manifiesto la clara inspiración de Francisco de Asís para el pontífice del que comenta :"Era un místico y un peregrino que vivía con simplicidad y en una maravillosa armonía con Dios, con los otros, con la naturaleza y consigo mismo. En él se advierte hasta qué punto son inseparables la preocupación por la naturaleza, la justicia con los pobres, el compromiso con la sociedad y la paz interior" FRANCISCO, Vaticano II, Laudatio Si, 2015 LS, 10. Dos meses más tarde, en mayo el Papa manifestó su intención de publicar una encíclica con especial interés medioambiental. El texto pontificio surgió tras el diálogo con científicos, expertos en temas medioambientales, teólogos y líderes de otras religiones. Su publicación se produjo dos años más tarde, el 18 Junio de 2015.La encíclica, que consta de 6 capítulos, 246 números y 200 páginas, supone una "reflexión gozosa y dramática a la vez". El Papa Francisco, incide en la urgente necesidad de crear un sistema normativo que ponga límites a la degradación de los ecosistemas y garantice su protección.

${ }^{16}$ Vease aquí Agenda 2030 para el Desarrollo Sostenible. Naciones Unidas 25 septiembre, 2015 .https://unctad.org/meetings/es/SessionalDocuments/ares70d1_es.pdf

17 EN HTTP://WWW.AR.UNDP.ORG/CONTENT/ARGENTINA/ES/HOME/PRESSCENTER/ ARTICLES/2016/06/15/DI-LOGOS-SOBRE-LAUDATO-S-Y-LOS-OBJETIVOS-DEDESARROLLO-SOSTENIBLE.HTML
} 
científicos que excluyen lo espiritual y axiológico en todos los ámbitos de la vida ${ }^{18}$.

Para los creyentes Dios ha creado el mundo de la nada haciéndose partícipe del mismo por puro amor y gratuidad. La visión sistemática, lateral e integral es uno de los puntos clave de esta encíclica para entender "el misterio de que todas las cosas en la creación están interconectadas entre sí y a su vez con Dios. Todos los seres forman parte de Dios y están relacionados entre sí de tal manera que unos necesitamos de otros para vivir" ${ }^{19}$.

Esta encíclica no sólo expone los males que acechan y amenanzan la creación, sino que sugiere una serie de cambios y propuestas que hagan surgir una nueva visión y mentalidad acerca de esta realidad. En el análisis de las causas de la crisis ecológica se observa que tanto la degradación ambiental como la social hunden sus raíces en tres causas vitales, a saber la generalización del individualismo, la exaltación y la dependencia de la tecnología y su lógica de poder ilimitado, lo que lleva a una comprensión del ser humano desde un relativismo puramente práctico."El ser humano se coloca a sí mismo en el centro, (...) dando prioridad absoluta a sus conveniencias circunstanciales, y donde todo lo demás se vuelve relativo" ${ }^{20}$ La Doctrina Social de la Iglesia comparte la idea de que la crisis ecológica tiene su origen en el hombre y sin el hombre no se puede hablar de ecología. El hombre y la tecnología han mejorado la calidad de vida pero al mismo tiempo, se ha generado una degradación del medio ambiente y un empobrecimiento debido a que esa mejora no ha repercutido en beneficio de todos por igual ${ }^{21}$.

Este dibujo de la humanidad actual que conforma la llamada sociedad liquida de Bauman y que tan agudamente describe Harari ${ }^{22}$, en palabras del propio Papa pone de manifiesto "un exceso de

\footnotetext{
${ }^{18}$ Sólo desde esa perspectiva de amor y gratuidad podemos entender que la creación quede sometida y dominada por el hombre. Un dominio que surge desde el amor y orientado hacia él

${ }^{19}$ Esta encíclica tiene su raiz en la tradición cristiana y como explica el Papa Francisco en la Exhortación Evangeli Gaiudium, "la doctrina social no es un añadido periférico u opcional a la fe cristiana, sino que forma parte del Kerygma" (EG 177-179). En palabras de San Juan Pablo II "Jesucristo... es el centro del cosmos y de la historia" (Encíclica Redemptor Hominis, 1). También las Sagradas Escrituras nos recuerdan " Todo ha sido creado por El y para El, El es anterior a todo y en El tiene todo su consistencia" (Col 1, 16-17). De estos textos , extraemos que Jesucristo está presente en toda la creación y en toda acción.

${ }^{20}$ FRANCISCO, Vaticano II, Laudatio Si, 2015 LS, 122.

${ }^{21}$ Vease tambien GUERRA SIERRA, A:Salvaguardar el medio ambiente .Reflexiones sobre el capítulo décimo del Compendio de la Doctrina Social de la Iglesia, EIUNSA 2012

${ }^{22}$ HARARI Y.N.: 21 lecciones para el siglo XXI, trad Joandomènec Ros i Aragonès, Debate, 2018.
} 
antropocentrismo". Hay que volver a establecer un orden situando al ser humano en el lugar que le corresponde. De esta forma, el Santo Padre concibe la ecología como ecología integral que establece un vínculo entre los asuntos ambientales y las cuestiones sociales humanas. "Este vínculo no debe romperse nunca porque no hay dos crisis separadas, una ambiental y otra social, sino una única y compleja crisis socio-ambiental...el equilibrio entre el cuidado de la naturaleza y las actividades del ser humano, debe pasar por una forma nueva de relacionarse con la naturaleza. "No hay ecología sin una adecuada antropología" insiste. ${ }^{23}$.

\subsection{TECNOLOGÍA, ECOLOGÍA Y HUMANIDAD}

El Papa reconoce la tecnología como capacidad con valor alegrándose de los avances técnicos, "especialmente en la medicina, la ingeniería y las comunicaciones al servicio de la humanidad ${ }^{24}$.También reconoce su versión corrupta que se manifiesta en el ansia de poder que carece de "una ética sólida, una cultura y una espiritualidad que realmente limite y contenga" a la posible capacidad de destruir el mundo y al mismo hombre ${ }^{25}$ En este sentido el Papa señala que "se ha vuelto tan dominante que es muy difícil prescindir de sus recursos, y más difícil todavía es utilizarlos sin ser dominados por su lógica" ${ }^{26}$ Su disimulada y engañosa neutralidad nos seduce condicionando nuestros estilos y modos de vida ${ }^{27}$, haciéndonos encima creer que los problemas generados por dicha lógica

\footnotetext{
${ }^{23}$ FRANCISCO, Vaticano II, Laudatio Si, 2015 LS, 1181 Una mirada al concepto de antropocentrismo: nos pone de manifiesto la postura del relativismo práctico, es decir, "el ser humano se coloca a sí mismo en el centro, (...) dando prioridad absoluta a sus conveniencias circunstanciales, y todo lo demás se vuelve relativo" FRANCISCO,Op.cit LS, 122. También ha de tenerse en cuenta en palabras del Papa que "El mundo está subordinado a la lógica de la técnica que es la lógica del "usar y tirar" FRANCISCO, Op.cit LS, 123. Expresado en otras palabras "cuando la técnica desconoce los grandes principios éticos, termina considerando legítima cualquier práctica" FRANCISCO, Op.cit LS, 136. La tecnología será legítima en palabras de San Juan Pablo II, "si actúa en la naturaleza para ayudarla a desarrollarse en su línea, la de la creación, la querida por Dios" FRANCISCO, Op.cit LS, 132. En definitiva para el Papa Francisco, "una ecología integral, que no excluya al ser humano, es indispensable incorporar el valor del trabajo" FRANCISCO, Op.cit LS, 124. El Pontífice defiende el derecho y la necesidad a que toda persona tenga acceso al trabajo y a limitar la sustitución de personas por máquinas FRANCISCO, Op.cit LS, 127 y 128.

${ }^{24}$ FRANCISCO, Vaticano II, Laudatio Si, 2015 LS, 102.

${ }^{25}$ FRANCISCO, Op.cit LS, 105.

${ }^{26}$ FRANCISCO, Op.cit LS, 108.

${ }^{27}$ FRANCISCO, Op.cit LS, 107.
} 
tecnocrática serán exclusivamente resueltos con más avances tecnológicos ${ }^{28}$.

Acude a la libertad del hombre como el contrapeso que es "capaz de limitar la técnica, orientarla y colocarla al servicio de otro tipo de progreso más sano, más humano, más social, más integral". Plantea la "cultura ecológica" que posee "una mirada distinta, un pensamiento, una política, un programa educativo, un estilo de vida y una espiritualidad que conformen una resistencia ante el avance del paradigma tecnocrático" 29. Esta cultura ecológica supone una auténtica revolución cultural capaz de percibir la no neutralidad de la ciencia y la tecnología con la valentía de aminorar la velocidad y modos de crecimiento, con la disposición de recoger los avances positivos y sostenibles para "recuperar los valores y los grandes fines del hombre, arrasados por un desenfreno megalómano" 30 .

En resumen, se trata de iluminar "la conciencia de nuestro origen común, de una pertenencia mutua y de un futuro compartido por todos" para así desarrollar nuevos modos de vivir y relacionarse ${ }^{31}$.

El ser humano autorreferencial, consumista y aislado de la actualidad debe convertirse en un ser por una parte consciente de la responsabilidad social, moral y económica de todos sus $\operatorname{actos}^{32} \mathrm{y}$ además consciente de que la sostenibilidad ambiental, la justicia, la paz y la vida dependen de la "capacidad de salir de sí hacia el otro" "As3 .Así pues tanto para el Papa Francisco como para su antecesor Benedicto XVI, la crisis ecológica es fruto de una crisis del hombre.

La solución a esta crisis ecológica no es nada fácil y el Papa propone la conversión ecológica, la colaboración y el diálogo como vías. La conversión ecológica supone tener conciencia de que todo lo recibimos con gratitud y se entrega y comparte desde la gratuidad ${ }^{34}$ la colaboración y el diálogo se resumen en la necesidad de establecerlos a escala internacional para tratar de conseguir un consenso global, por un lado sustituyendo la "tecnología basada en combustibles fósiles muy

\footnotetext{
${ }^{28}$ FRANCISCO, Op.cit LS, 109.

${ }^{29}$ FRANCISCO, Op.cit LS, 111.

${ }^{30}$ FRANCISCO, Op.cit LS, 114.

${ }^{31}$ FRANCISCO, Op.cit LS, 202.

${ }^{32}$ FRANCISCO, Op.cit LS, 206.

${ }^{33}$ FRANCISCO, Op.cit LS, 207 y 208.

${ }^{3434}$ FRANCISCO, Op.cit LS, 220.
} 
contaminantes" y al mismo tiempo asumir responsabilidades conjuntas que eviten la especulación medioambiental ${ }^{35}$.

La Naturaleza expresada a través de la creación es un patrimonio común, responsabilidad de todos de forma que la dialéctica de los intereses en juego esté sujeta al derecho evitando malas prácticas y fomentando la creatividad y el emprendimiento en la aplicación de economía circular ${ }^{36}$.

\subsection{CUIDAR DE LA CASA COMÚN, OBLIGACIÓN DE TODOS}

Desde el concepto de Aldea de Global McLuhan y Chomsky ${ }^{37}$, se han desarrollado múltiples compromisos que han cristalizado en el acuerdo de Paris sobre el cambio climático y en los Objetivos del Desarrollo Sostenible, debemos a Francisco la nomenclatura del cuidado de la casa común, donde las actuaciones individuales resultan imprescindibles. No se trata de llevar a cabo grandes hitos, sino en nuestra vida diaria cuidar de "nuestra casa común" con actos como el reciclado, uso del transporte público, uso razonable del agua...actos de amor al prójimo, a los pobres, a aquellos que más sufren la crisis ecológica apuntaba el Papa en 2015, que formulaba la siguiente pregunta: “¿Qué tipo de mundo queremos dejar a quienes nos sucedan, a los niños que están creciendo?"38. Como indica la estrategia española sobre cambio climático "El cambio climático es una de las principales amenazas para el desarrollo sostenible, representa uno de los principales retos ambientales con efectos

\footnotetext{
${ }^{35}$ FRANCISCO, Op.cit LS,164 y ss El Papa señala que la dignidad, el desarrollo y ecología humana están interrelacionadas estableciéndose un vínculo entre ellas. En este sentido se encuentra también la aspiración de "construir una civilización de solidaridad mundial" que indicó el Beato Pablo VI en Popularum progressio 1967.

${ }^{36}$ En los últimos años han surgido nuevos términos como la economía ecológica que para calcular en valor monetario la deuda ecológica que se está generando En este sentido desde las aportaciones de COMMON,M Y STAGL,S en Introducción a la economía ecológica Reverte Editorial Sa, 2008 hasta la actual economía circular se encuentran determinadas las correcciones que deben operarse en el actual sistema productivo .El Papa señala la necesidad urgente de que "la política y la economía, en diálogo, se coloquen decididamente al servicio de la vida, especialmente de la vida humana" hace falta desacelerar el actual ritmo de crecimiento productivo y de consumo y establecer límites al actual modelo tecnocrático de desarrollo A nivel político, respetar el principio de subsidiariedad, la visión integral e interconectada del mundo, y un diálogo interdisciplinario FRANCISCO,Op.cit LS, 189 -195. 37 McLuhan M y Powers B. R. La aldea global: transformaciones en la vida y los medios de comunicación mundiales en el siglo XXI Gedisa, 1990 Chomsky, N y Dieterich H La aldea global Txalaparta, 1997 - 207

${ }^{38}$ FRANCISCO, Op.cit LS, 160.
} 
sobre la economía global, la salud y el bienestar social. Sus impactos los sufrirán aún con mayor intensidad las futuras generaciones" ${ }^{\text {" }}$ La esperanza no debe quedar lejos de aunar esfuerzos para lograr un futuro sostenible, un mundo sin desigualdades, sin hambre, sin pobreza, con acceso a los recursos naturales, a la educación, donde se proteja el medioambiente, y se logre la paz entre los países.

Como indica Mendez Rocasolano “... abriéndose, en términos de igualdad, un diálogo entre la categoría poder y la propia de los derechos humanos, fundamento del método dialéctico, observamos una relación tensa, donde el derecho al desarrollo está definido por el progreso y la realidad de la dignidad humana en conjunción con el poder económico y sus múltiples significaciones, en este sentido la profesora aporta la idea del desarrollo como derecho de la humanidad ${ }^{40}$ ya que es responsabilidad de toda la humanidad "el cuidado de la casa común". Este concepto de humanidad como sujeto de derechos todavía en vía de consolidarse inspira posibles actuaciones que reduciendo desigualdades vinculen a los hombres en tareas comunes. En este sentido la Laudato Sí, promueve el diálogo entre no creyentes, no católicos y católicos ${ }^{41}$. De hecho no es casualidad que tres meses después de la publicación de la encíclica, tuviese lugar la aprobación de los nuevos Objetivos de Desarrollo Sostenible, en la cumbre

\footnotetext{
${ }^{39}$ Estrategia española sobre cambio climático

${ }^{40}$ MÉNDEZ ROCASOLANO M. y OLIVEIRA DA SILVEIRA, V.: "Derechos humanos, desarrollo y poder, una relación comprometida" III Encontro de Internacionalização Do Conpedi Madrid /Espanha. Direito Constitucional Direitos Humanos. 2, 2014. pág. 143 - 172.

${ }^{41}$ En este sentido, se celebró en Madrid Septiembre de 2016, la Jornada Mundial de Oración por el Cuidado de la Creación entre católicos y ortodoxos, instituida por el Papa Francisco el 1 de Septiembre de 2015. Por iniciativa del patriarcado de Constantinopla, las iglesias ortodoxas dedican su primer día del año litúrgico, coincidiendo con este día, a alabar y orar a Dios por la creación y su cuidado. Esta Jornada organizada en Madrid supone que "por primera vez en España católicos y ortodoxos constituyan una comisión mixta de trabajo con vocación de continuidad". (Carlos Jesús Delgado, vicepresidente de Justicia y Paz en Madrid). En este encuentro el arzobispo de Madrid, monseñor Carlos Osoro, monseñor Policarpo, metropolita de España y Portugal del Patriarcado de Constantinopla y monseñor Timotei, obispo ortodoxo rumano de España y Portugal firmaron una declaración conjunta y abierta a más personas. En el texto se subraya: "Los crímenes contra la naturaleza y contra nuestros hermanos son un despropósito ante nuestra propia dignidad humana y un pecado contra Dios, porque nos hemos considerado dueños y señores en lugar de administradores y colaboradores de Dios. La crisis ecológica actual supone un reto enorme. El ser humano todavía es capaz de intervenir positivamente, porque ha sido creado para amar". Entre los temas que se trataron, destacar los problemas ambientales en la ciudad de Madrid como la gestión de residuos, mala calidad del aire, exceso de ruido, errores en infraestructuras y construcción urbanística...Para hacer frente a estos problemas, se plantearon iniciativas como reducir el uso de medios de transporte contaminantes como (avión, coche...), uso de energías renovables, uso de bombillas de bajo consumo... Vemos en definitiva como las líneas para la solución requieren una aproximación integral para combatir la pobreza, para devolver la dignidad a los excluidos y simultáneamente para cuidar la naturaleza". FRANCISCO, Op.cit LS, 67
} 
inaugurada por el Papa en la sede de la ONU en Nueva York (25 de Septiembre 2015). Plantean una solución para lograr un futuro sostenible, y así se adoptaron por todos los Países Miembros de las Naciones Unidas con la meta de su cumplimiento para el 2030. En ellos se plantea una transformación integral y ecuménica para los países cuyo epicentro gire en torno a la sociedad y el medioambiente.

Para Benigno Rodriguez, Representante Residente Adjunto del Programa de Naciones Unidas para el Desarrollo, la publicación de Laudato Sí supuso:" un faro que alumbró un año de decisiones de gran importancia global: la Agenda 2030 y los Objetivos de Desarrollo Sostenible junto al Acuerdo de París sobre Cambio Climático, se inscriben en esa línea" 42 . En este sentido han de destacarse los que a juicio del ministerio de transición ecológica son los principales resultados de la COP21 que coinciden con los elementos del Acuerdo de París. Su objetivo fundamental implica la que el incremento de la temperatura media global no supere los $2^{\circ} \mathrm{C}$ respecto a los niveles preindustriales para el calentamiento global no supere los $1,5^{\circ} \mathrm{C}$ para ello se pretende que las emisiones globales toquen techo lo antes posible. También se pone en valor la importancia de adaptarse a los efectos adversos del cambio climático, como será el aumento de la migración humana, estableciendo un objetivo global de aumento de la capacidad de adaptación y reducción de la vulnerabilidad, en un contexto en el que todos los países se están enfrentando a los impactos derivados del cambio climático. En definitiva sienta las bases para una transformación hacia modelos de desarrollo bajos en emisiones. ${ }^{43}$

Al respecto el Papa, se pronuncia en tres aspectos respecto al cambio climático: en primer lugar plantea la necesidad de un consenso a

\footnotetext{
${ }^{42}$ Acuerdo de París, alcanzado en la XXI Conferencia internacional sobre el Cambio Climático, o 21 conferencias de las partes (COP 21) donde participaron 195 países. (Le Bourget, 30 noviembre-11 diciembre, 2015) "Laudato Sí, marca sin duda, la necesidad de realizar una revisión profunda de nuestro proceder individual y colectivo para el cuidado de nuestra "Casa Común", con un alcance inclusivo y ecuménico (...) es un documento integral e integrador que vincula a la persona con la naturaleza, con la creación, en un marco de respeto de la diversidad y de las principales cosmovisiones de la fe, para encontrar un camino de diálogo común a todos".

${ }^{43}$ Se diferencia entre los países que están todavía en desarrollo incluyéndose la reducción de emisiones a medio y largo plazo de gases de efecto invernadero para lograr un equilibrio entre sus emisiones y las absorciones. Ha puesto un importante montante económico al servicio de esta finalidad - 100.000 millones de dólares anuales, a partir de 2020 -y además compromete a todos los países a que, cada cinco años, comuniquen y mantengan sus objetivos de reducción de emisiones, así como la puesta en marcha de políticas y medidas nacionales para ello. Para más información véase https://www.miteco.gob.es/es/cambio-climatico/temas/cumbre-cambio-climatico-cop21/resultadoscop-21-paris/default.aspx
} 
nivel científico y con carácter internacional sobre el calentamiento global, debido a la enorme concentración de gases efecto invernadero (óxido de nitrógeno, metano, anhídrido carbónico...). Estos podrían ir a peor si no modificamos los actuales hábitos de consumo y actividades de producción. En segundo respecto a la brecha entre países de Norte y Sur, la diferencia o "deuda ecológica" indica que se vería reducida si los países más desarrollados disminuyeran el consumo de energía no renovable y apostasen por políticas de ayudas al desarrollo sostenible para los más pobres. Y finalmente, en tercer lugar denuncia el Interés de los países más poderosos de enmascarar los efectos devastadores el cambio climático. ${ }^{44}$

Dentro de este marco la Asamblea General de las Naciones Unidas (ONU) aprobó en pleno la agenda denominada "Transformar nuestro mundo: la Agenda 2030 para el Desarrollo Sostenible" (ONU, $2015)^{45}$. Que a través de Los Objetivos del Desarrollo Sostenible pretende "fortalecer la paz universal dentro de un concepto más amplio de la libertad" y reconoce que "la erradicación de la pobreza en todas sus formas y dimensiones, incluida la pobreza extrema, es el mayor desafío a que se enfrenta el mundo y constituye un requisito indispensable para el desarrollo sostenible" 46 .

Los Objetivos del Desarrollo Sostenible abarcan distintas áreas, algunas de ellas ya tratadas en los Objetivos del Milenio, pero suponen importantes novedades que incluyen dimensiones sociales, medioambientales, económicas, espirituales y un firme compromiso de que ningún país se quede rezagado evitando así desequilibrios. Fueron propuestos de forma participativa, tras una amplia consulta a nivel mundial. Unos días antes de la celebración de la Cumbre del Cambio Climático, en Nairobi el Papa propuso cuatro principios "solidaridad,

\footnotetext{
44 "Si seguimos consumiendo como hasta ahora, no hay suficientes molinos de viento en el mundo para sostenerlo. Esta crisis medioambiental refleja una crisis espiritual que hay que reparar". Indica el Rabino Yonatan Neril, fundador del Centro Interreligioso de Desarrollo Sostenibleen http://www.revistapalabra.es/rabino-yonatan-neril-las-crisis-ecologica-espiritual-globales-requierencolaboracion-las-religiones/

${ }^{45}$ Agenda 2030 para el Desarrollo Sostenible" ONU, 2015, Naciones Unidas, Treaty Series, vol. 1771, núm. 30822.pág 2. La Agenda 2030 para el Desarrollo Sostenible, surge como extensión de los Objetivos de Desarrollo del Milenio y tras un intensa consulta con expertos a nivel técnico, político y social de cada país, y de los ciudadanos consultados mediante la Encuesta "Mi Mundo 2015". La Agenda define 17 objetivos y 169 metas, combinando la dimensión económica, social y ambiental para lograr un desarrollo sostenible.

46 Interesa la consulta de Naciones Unidas A/73/581 Asamblea General 3 de diciembre de 2018 Septuagésimo tercer período de sesiones. Informe de la Tercera Comisión Relatora: Sra. Katharina Konzett-Stoffl (Austria).
} 
justicia, equidad y participación" 47 . Y tres objetivos: "el alivio del impacto del cambio climático, la lucha contra la pobreza y el respeto de la dignidad humana", expresando de esta forma su deseo de llegar a un acuerdo internacional. Al final quedaron los siguientes:

1. Fin de la pobreza: en todas sus formas y en todo el mundo.

2. Hambre Cero: Erradicar el hambre, lograr la mejora de la nutrición, seguridad alimentaria y promover la sostenibilidad en la agricultura.

3. Salud y bienestar: Garantizar una vida sana y promover el bienestar para todos.

4. Educación de calidad: Garantizar una educación inclusiva, equitativa y de calidad y promover el aprendizaje durante toda la vida para todos.

5. Igualdad de género: lograr la igualdad y empoderar a las mujeres y niñas.

6. Agua limpia y saneamiento: Garantizar el acceso al agua, su gestión sostenible, y el saneamiento para todos.

7. Energía asequible y no contaminante: Garantizar el acceso a una energía asequible, segura, sostenible y moderna.

8. Trabajo decente y crecimiento económico: Promover el crecimiento económico sostenido, inclusivo y sostenible, el pleno empleo, productivo y el trabajo decente.

9. Industria, innovación, infraestructura: Construir infraestructuras resilientes, promover una industria inclusiva y sostenible $\mathrm{y}$ fomentar la innovación.

10. Reducción de las desigualdades en y entre los países

11. Ciudades y comunidades sostenibles: Conseguir ciudades y asentamientos humanos inclusivos, seguros, resilientes y sostenibles.

12 Producción y consumo responsable: Garantizar un consumo y producción sostenibles

13. Acción por el clima: Adoptar medidas urgentes para combatir el cambio climático y sus efectos.

14. Vida submarina: Conservar de forma sostenible los océanos, los mares y los recursos marinos para el desarrollo sostenible.

${ }^{47}$ Son los principios que el Papa había propuesto a los ministros de Medio Ambiente de la Unión Europea. (16 septiembre, 2015). Para el cumplimiento de los Objetivos del Desarrollo Sostenible el Papa Francisco hace una llamada en cuanto al modelo energético propone su cambio por un modelo ecológico que garantice el desarrollo sostenible "La cuestión energética se ha convertido en uno de los principales desafíos, teóricos y prácticos, para la comunidad internacional. De cómo sea administrada dependerá la calidad de la vida y si los conflictos presentes en diversas áreas del planeta encuentran una fácil solución, o quizás, si estas, a causa de profundos desequilibrios ambientales y de la penuria de la energía, encontraran nuevo combustible para alimentarse, quemando la estabilidad social y vidas humanas. La civilización necesita energía, pero el uso de la energía no debe destruir la civilización" explicó el Papa. A los dos años y medio del tratado de Paris, las emisiones de CO2 y la concentración atmosférica de gases de efecto invernadero sigue siendo muy alta. Esto es muy inquietante y preocupante". Por este motivo se reunió en el Vaticano con los responsables de importantes compañías energéticas internacionales y relacionadas con esa actividad (Exxon Mobil, British Petroleum, Royal Dutch Shell, Pemex, ENI, Equinor, Black Rock...).Véase https://int.corresponsables.com/actualidad/papa-francisco-transicion-energetica 
15 Vida de ecosistemas terrestres: Proteger, restablecer y promover el uso sostenible de los ecosistemas terrestres, efectuar una ordenación sostenible de los bosques, luchar contra la desertificación, detener y revertir la degradación de las tierras y poner freno a la pérdida de diversidad biológica.

$16 \mathrm{Paz}$, justicia e instituciones sólidas: Promover sociedades pacíficas e inclusivas para el desarrollo sostenible, facilitar el acceso a la justicia para todos y crear instituciones eficaces, responsables e inclusivas a todos los niveles

17 Alianzas para lograr los objetivos: Fortalecer los medios de ejecución y la alianza mundial para el desarrollo sostenible.

\section{3

$\begin{array}{llll}\text { CONOCIMIENTO } & \text { Y RESPONSABILIDAD } & \text { SOCIAL } \\ \text { UNIVERSITARIA COMO EJES } & \text { DEL } & \text { NUEVO } \\ \text { PARADIGMA SOCIAL CONTRA EL CAMBIO } \\ \text { CLIMÁTICO E IMPULSO DE LA ECONOMÍA CIRCULAR }\end{array}$

A pesar de que el cambio climático es una realidad todavía hay una parte de la población que desconoce su gravedad y consecuencias, con la retirada de EEUU en el 2017 se ha dejado de cumplir con la condición para la entrada en vigor del acuerdo ser ratificado por más de 55 partes que suman más del 55 por ciento de las emisiones globales de gases de efecto invernadero. ${ }^{48}$

Los efectos cómo la disminución de la biodiversidad y el calentamiento global, son adversos a la humanidad, aumenta del número de enfermedades, y la pobreza sin remedio. Para dar cumplimiento al derecho al desarrollo sostenible de los pueblos y sus poblaciones los Objetivos del Desarrollo Sostenible y la Laudatio si plantean considerar el planeta como la casa común de la que todos somos responsables. En este sentido, el Santo Padre se pronuncia: "Al mismo tiempo, si se quiere conseguir cambios profundos, hay que tener presente que los paradigmas de pensamiento realmente influyen en los comportamientos. En este sentido la formación y la educación resulta fundamental. La educación será ineficaz y sus esfuerzos serán estériles si no procura también difundir un

\footnotetext{
${ }^{48}$ Donald Trump anuncia que Estados Unidos abandonará el Acuerdo de París sobre cambio climático, ver también Shear, Michael D. (1 de junio de 2017). «Trump anuncia que retirará a Estados Unidos del Acuerdo de París sobre el cambio climático». The New York Times. 6 de junio de 2017.Para algunos son exageradas las cifras, y otros no son capaces de reducir el ritmo de consumo o cambiar su estilo de vida ALBAREDA, S., Reconciliarse con el planeta. La sostenibilidad como paradigma. Pamplona: Eunsa, 2015, pág 148 y ss propone ejemplos que vinculan la responsabilidad social y medioambiental con las decisiones individuales.
} 
nuevo paradigma acerca del ser humano, la vida, la sociedad y la relación con la naturaleza. De otro modo, seguirá avanzando el paradigma consumista que se transmite por los medios de comunicación y a través de los eficaces engranajes del mercado" 49.

Centrados en la educación universitaria, surge la Responsabilidad Social Universitaria que en palabras de Vallaeys, es "una política de calidad ética del desempeño de toda la comunidad universitaria (estudiantes, docentes y personal administrativo) mediante la gestión responsable de los impactos educativos, cognitivos, laborales, sociales y ambientales generados por la Universidad, en un ambiente de diálogo participativo con la sociedad para promover el Desarrollo Humano Sostenible" 50 .

A través de la Responsabilidad Social Universitaria se recoge el espíritu de la paidea isocratica que pretende mejorar la sociedad, este objetivo para la defensa y promoción de la ecología, del cuidado y protección de la naturaleza establece un vinculo de la Universidad con el mundo a través de los docentes y los alumnos que pueden convertirse en agentes de conocimiento y transformación social ${ }^{51}$. En concreto en España, la normativa que regula la Responsabilidad Social Universitaria indica que los planes de estudios tendrán en cuenta que cualquier actividad profesional debe realizarse: a) desde el respeto a los derechos fundamentales y de igualdad entre hombres y mujeres, debiendo incluirse, en los planes de estudios en que proceda, enseñanzas relacionadas con dichos derechos. b) desde el respeto y la promoción de los Derechos humanos y los principios de accesibilidad universal y diseño para todos de conformidad con lo dispuesto en la disposición final décima de la ley 51/2003, de 2 de diciembre, de Igualdad de oportunidades, no discriminación y accesibilidad universal de las personas con discapacidad, debiendo incluirse, en los planes de estudio en los que proceda, enseñanzas relacionadas con dichos derechos y principios. c) de acuerdo con los valores propios de la cultura de paz y de valores democráticos, y debiendo

\footnotetext{
${ }^{49}$ FRANCISCO, Op.cit LS, 215

${ }^{50}$ VALLAEYS, F., DE LA CRUZ, C. Y SASIA, P. (2009). Responsabilidad Social

Universitaria. Manual de primeros pasos. México D.F.: McGraw Hill.

${ }^{51}$ Desde el 2003 la profesora MÉNDEZ ROCASOLANO viene insistiendo en la vinculación de la Universidad en la tarea de hacer efectiva la paideia, influenciada por su maestro Lucas Verdú, la entiende como un elemento básico para el desarrollo de la politeia. Para un estudio más detenido sobre el asunto véase "Innovación docente desde el modelo tridimensional del conocimiento expandido y la paideia hacia la Cultura y la Democracia" en Nuevas formulaciones de los contenidos docentes / coord. por Javier Fombona Cadavieco, David Caldevilla Domínguez, 2014.
} 
incluirse, en los planes de estudios en los que proceda, enseñanzas relacionadas con dichos valores." 52

En concreto la Ley de Economía Sostenible estipula que la extensión y la mejora de la calidad de la educación e impulso de la formación continua, es uno de los principales ámbitos de actuación para impulsar la sostenibilidad de la economía española, así como para mejorar la cohesión social y el desarrollo personal de los ciudadanos. En relación con lo anterior, su artículo 60 señala que para la consecución de un desarrollo económico sostenible, el sistema universitario español promoverá "la calidad, la competitividad e internacionalización de las universidades mediante la especialización formativa e investigadora, la modernización de sus infraestructuras y la mejora de la eficiencia en su gestión, con un compromiso reforzado con el Espacio" $" 53$

Vinculadas a la Responsabilidad Social Universitaria en tanto que herramienta útil para hacer consciente a la sociedad y a los individuos de su necesaria participación fundamental para el cuidado del planeta están las actuaciones concretas que desde este marco se confeccionan en colaboración entre las empresas y las Universidades, destaca aquí la experiencia de las Cátedras de Responsabilidad Social Universitaria en España. Al respecto desde la Cátedra Internacional de Responsabilidad Social Corporativa de la Universidad Católica San Antonio de Murcia se han logrado extraordinarios resultados en materia de divulgación, formación y promoción de los Objetivos del Desarrollo Sostenible , los Derechos Humanos y la Protección ambiental, con un firme compromiso con las normas, la sociedad civil y representantes empresariales e institucionales que se alían estratégicamente para modernizar el ámbito universitario a partir de una formación e investigación dirigida a fomentar

\footnotetext{
${ }^{52}$ Artículo 3 apartado 5d el Real Decreto 1393/2007 de 29 de Octubre, que establece la ordenación de enseñanzas universitarias oficiales . Véase también la Ley Orgánica 4/2007 del 12 de abril de Universidades. Dentro de los principales documentos, y/o pronunciamientos legales e institucionales de España en materia de RSU: https://rsuniversitaria.org/ Entre otras normas en España destacan: Libro Blanco de la Comisión Europea sobre la Responsabilidad Medioambiental, publicado en febrero del año 2000.Ley 9/2006 de 28 de abril, sobre la evaluación de los efectos de determinados planes y programas en el medio ambiente.-La Ley Orgánica 4/2007 de 12 de abril, por la que se modifica la Ley Orgánica 6/2001 de 21 de diciembre de Universidades (LOMLOU), expone entre sus objetivos la necesidad de conseguir una mayor autonomía de las universidades, así como responder a las demandas de la sociedad y el sistema productivo, logrando una mejor formación a cualquier edad de sus titulados y tituladas, que les permita adaptarse en las mejores condiciones a dichas demandas. - Libro Blanco de la UE sobre la Adaptación al cambio climático: Hacia un marco europeo de actuación, publicado en abril del año 2009.

${ }^{53}$ https://www.boe.es/buscar/act.php?id=BOE-A-2011-4117
} 
los valores, especialmente los que llenan de contenido al derecho al medio ambiente adecuado para el desarrollo de la persona ${ }^{54}$.

Cercano ya el horizonte 2020 pensemos que "Las predicciones catastróficas ya no pueden ser miradas con desprecio e ironía. A las próximas generaciones podríamos dejarles demasiados escombros, desiertos y suciedad. El ritmo de consumo, desperdicio y de alteración del medio ambiente ha superado las posibilidades del planeta, de tal manera que el estilo de vida actual, por ser insostenible, sólo puede terminar en catástrofes, como de hecho ya está ocurriendo periódicamente en diversas regiones. La atenuación de los efectos del actual desequilibrio depende de lo que hagamos ahora mismo, sobre todo si pensamos en la responsabilidad que nos atribuirán los que deberán soportar las peores consecuencias" ${ }^{\text {"55. }}$.

El consumo responsable y la ecología que precisa de una justa gestión de los recursos naturales. Es responsabilidad de cada ser humano... "me gustaría llamar la atención de todos, ciudadanos, autoridades del país, socios internacionales y empresas multinacionales, acerca de la grave responsabilidad que les corresponde en la explotación de los recursos medioambientales, en las opciones y proyectos de desarrollo, que de una $u$ otra manera afectan a todo el planeta. La construcción de una sociedad próspera debe ser una obra solidaria" dijo el Papa en Bangui, capital de la República Centroafricana ${ }^{56}$, y en esa solidaridad la responsabilidad también ha de ser universitaria.

\section{CONCLUSIONES}

Ante la multitud de ideologías y concepciones del mundo que, desde diferentes perspectivas afrontan el futuro de la humanidad, la Iglesia siente la urgente necesidad de pronunciarse. Y quiere hacerlo desde una lógica a la vez trascendente e inmanente. La encíclica lleva a cabo aportaciones que resultan novedosas en su exposición respecto a sus predecesores. Ha tenido un impacto y reconocimiento a nivel internacional

\footnotetext{
${ }^{54}$ La Cátedra Internacional de Responsabilidad Social UCAM nace con el objetivo de dinamizar la inquietud por el impulso de la RS de empresas, organizaciones no lucrativas, administraciones públicas, profesionales, estudiantes y sociedad en general. Para mayor información véase https://www.ucam.edu/universidad/catedras/catedra-internacional-de-responsabilidad-socialcorporativa

${ }^{55}$ FRANCISCO, Op.cit LS, 215

${ }^{56} \mathrm{http}: / /$ www.iglesia.cl/detalle_noticia.php?id=29584
} 
ejerciendo influencia en los acuerdos que se llevaron a cabo en 2015 en materia de desarrollo sostenible.

La Doctrina Social de la Iglesia, marcada por grandes hitos como son las encíclicas "Rerum novarum", "Mater et Magistra", "Centesimus annus", "Pacem in terris" o Populorum progressio", postula el planteamiento de una ecología integral como una ampliación de la misma doctrina con una completa y sistémica del desarrollo sostenible.

En la interpretación de la ecología integral a la que apunta la encíclica Laudatio Si no podemos olvidar algunos textos de Benedicto XVI sobre el mismo tema, ni las intuiciones contenidas en las encíclicas sociales mencionadas más arriba. Pero tampoco podemos dejar de lado influencias no provenientes del pensamiento bíblico, sino de autores como Schelling, cuyas concepciones idealistas fueron popularizadas por el filósofo Krause, conocido en España a través de Sanz del Río y de la Institución Libre de Enseñanza. Respecto a la creación de un sistema normativo para garantizar la protección, se trata de elaborar una ética y una normativa ecológica integrales, eso sí, evitando cualquier devaluación de la moral individual, que, fácilmente nos llevaría a una ética situacionista o existencialista.

La necesidad de abordar la problemática social y ambiental de manera integral se manifiesta a través de una "conversión ecológica integral" con clara influencia de Teilhard De Chardin . Esta conversión no es sólo a nivel espiritual, sino también en la forma de pensar y actuar del ser humano y así poder pasar del conflicto al diálogo ${ }^{57}$. Se precisa la dialéctica para encontrar soluciones reales para afrontar la crisis socioambiental que precisa de la promoción de la sostenibilidad entre todos y para todos con independencia de las creencias o de los credos. El Papa hace una urgente llamada a cuidar de la casa común, a una responsabilidad ética en favor de la sostenibilidad. Nos muestra de forma explícita las interrelaciones en el ámbito social, ambiental y económico.

En lo referente a la amenaza que puede suponer para el futuro de la humanidad el potencial de la ciencia y la tecnología muchos pensadores y escritores ya se pronunciaron en este sentido. Citar a Karl Jaspers, que reflexionó con profundidad sobre la amenaza atómica. Y físicos como Oppenheimer se lamentaron de haber puesto armas de destrucción masiva en manos de los políticos. Mencionar a Huxley u Orwell y sus novelas de la "anti-utopía".

${ }^{57}$ TEILHARD DE CHARDIN, P.: Lo que yo creo Editorial Trotta, S.A., 2005 
Urge un cambio en un breve plazo, un cambio en la producción, el consumo de bienes y servicios y en nuestra relación con la naturaleza. Un aspecto importante a destacar de esta crisis socio-ambiental es que las acciones cotidianas del individuo acaban impactando en el proceso de degradación medioambiental. Por eso, la solución no depende sólo de las grandes empresas y gobiernos, sino también de las acciones individuales de las personas vinculadas todos a una economía circular y global capaz de regenerar la degradación y la crisis socioambiental que conlleva. Para ello se precisa de actuaciones concretas en el área de la educación ambiental y su transferencia que nos muestren la realidad.

En el ámbito de educación universitaria, el desarrollo de la concienciación ambiental a través de la formación y la investigación ambiental tiene en el ejercicio de la Responsabilidad Social Universitaria una dimensión de contrapeso a la crisis ecológica que se materializa en actuaciones concretas de diálogo entre el mundo universitario y la sociedad civil. Los objetivos del Desarrollo Sostenible y las acciones concretas contra el cambio climático aliados con las exigencias normativas e institucionales junto con la Responsabilidad Social Universitaria tendrán un papel protagonista en la pretensión de lograr un mundo mejor para el próximo 2030.

\section{BIBLIOGRAFIA}

ALBAREDA, S., Reconciliarse con el planeta. La sostenibilidad como paradigma, Ed. EIUNSA, 2015.

ALBAREDA. S INICI T.:A "portaciones de la "Laudato sí" en el contexto de la Agenda 2030 para el Desarrollo Sostenible” Scripta Theologica Vol 48, No 2 ,2016.

AMESTOY ALONSO J.: El Planeta Tierra en peligro: Calentamiento Global, Cambio Climático, Soluciones, Ed. Club Universitario, 2013.

BENEDICTO XVI, Carta encíclica Caritas in veritate 29 de junio de 2009.

CASTELLS, M.: La Era de la información: economía, sociedad y cultura, Volumen 2, Ed. Siglo XXI, 2004.

CHOMSKY, N Y DIETERICH H La aldea global, Ed. Txalaparta, 1997.

COMMON,M Y STAGL,S.: Introducción a la economía ecológica Ed. Reverte, 2008.

DUARTE, C. M. (coord.), Cambio global. Impacto de la actividad humana sobre el planeta Tierra, Ed. CSIC, 2006. 
FRANCISCO, Carta encíclica Laudato si’. Sobre el cuidado de la casa común 24 de 2015.

GUERRA SIERRA, A: Salvaguardar el medio ambiente. Reflexiones sobre el capítulo décimo del Compendio de la Doctrina Social de la Iglesia, Ed. EIUNSA 2012.

HANSON, .K T. PUPLAMPU K. P., SHAW T. M. "From Millennium Development Goals to Sustainable Development Goals", Development Goals to Sustainable Developm Goals: Rethinking African Development, Ed. Routledge, The International Political Economy of New Regionalisms Series, 2017.

HARARI Y.N.: 21 lecciones para el siglo XXI, trad Joandomènec Ros i Aragonès, Ed. Debate, 2018.

JACOBS M.: La economía verde: medio ambiente, desarrollo sostenible y la política del futuro, Ed. Icaria, 1996.

JUAN PABLO II, Carta encíclica Centesimus annus 1 de mayo de 1991. . Carta encíclica Evangelium vitae 25 de marzo de 1995. . Carta encíclica Fides et ratio 14 de septiembre de 1988. . Carta encíclica Sollicitudo rei socialis 30 de diciembre de 1987. . Exhortación Apostólica Pastores gregis 16 de octubre de 2003.

LEFF E.: Saber ambiental: sustentabilidad, racionalidad, complejidad, poder, Ed. Siglo XXI, 2002.

MCLUHAN M Y POWERS B. R.: La aldea global: transformaciones en la vida y los medios de comunicación mundiales en el siglo XXI, Ed. Gedisa, 1990.

MÉNDEZ ROCASOLANO M. "Un reto de Derecho Constitucional y Ecología Política: el derecho fundamental al ambiente", Revista jurídica de la Universidade Portucalense 2000 .

. Ambiente y Derecho Ambiental Concepto y Fuentes Rodela, 2005.

. "Algunas consideraciones sobre la fundamentación axiológica del derecho a un ambiente adecuado para el desarrollo de la persona" Estudios de teoría del Estado y derecho constitucional en honor de Pablo Lucas Verdú / coord. por Raúl Morodo Leoncio, Pedro de Vega García, Vol. 3, Ed. Aranzadi, 2001.

. "Innovación docente desde el modelo tridimensional del conocimiento expandido y la paideia hacia la Cultura y la Democracia" en Nuevas formulaciones de los contenidos docentes / coord. por Javier Fombona Cadavieco, David Caldevilla Domínguez, : Mc Graw Hill Education 2014

OLIVEIRA DA SILVEIRA, V y MÉNDEZ ROCASOLANO M.: "Derechos humanos, desarrollo y poder,una relación comprometida" III Encontro de Internacionalização Do Conpedi Madrid /Espanha. Direito Constitucional Direitos Humanos. 2, Ed. Tecnos, 2014 TEILHARD DE CHARDIN, P.: Lo que yo creo Ed. Trotta, S.A., 2005 
VALLAEYS, F., DE LA CRUZ, C. Y SASIA, P. . Responsabilidad Social Universitaria. Manual de primeros pasos. Ed. McGraw Hill, 2009.

VVAA. COMISIÓN MUNDIAL DEL MEDIO AMBIENTE Y DEL DESARROLLO, Nuestro Futuro Común, Ed. Alianza, 1988. 